\title{
Visualization of 40 Years of Tropical Cyclone Positions and Their Rainfall Impacts in Central America
}

\author{
Franklin Hernández-Castro, ${ }^{1, A, B}$, Jorge Monge-Fallas ${ }^{2, A}$, Hugo G. Hidalgo3,C,D, \\ Eric J. Alfaro $4, \mathrm{C}, \mathrm{D}, \mathrm{E}$ \\ A Instituto Tecnológico de Costa Rica, Costa Rica \\ в Hochschule für Gestaltung Schwäbisch Gmünd, Alemania \\ C Centro de Investigaciones Geofísicas, Universidad de Costa Rica, San José, Costa Rica \\ D Escuela de Física, Universidad de Costa Rica, San José, Costa Rica \\ E Centro de Investigación en Ciencias del Mar y Limnología, Universidad de Costa Rica, \\ San José, Costa Rica \\ ${ }^{1}$ ORCID: oooo-0oo3-3589-4588, franhernandez@itcr.ac.cr \\ 2 ORCID: oooo-0002-1651-3543, , jomonge@itcr.ac.cr \\ 3 ORCID: o0oo-0003-4638-0742, hugo.hidalgo@ucr.ac.cr \\ 4 ORCID: 0000-0001-9278-5017, erick.alfaro@ucr.ac.cr
}

\begin{abstract}
This article focuses on a visualization of tropical cyclone track data occurring over a 40year period (1970-2010) and their relationship with (extremely) heavy rainfall reported by 88 Central American weather stations.

The purpose of the visualization is to associate the paths of tropical cyclones in oceanic areas with heavy rainfall inland. Thus, the potential for producing a set of rainfall patterns might somehow help in predicting where different impacts like flooding might occur when tropical cyclones develop in specific oceanic regions.

The visualization will serve as a key tool for CIGEFI scientists to apply in their work to determine critical positions of the tropical cyclones associated with extremely heavy rainfall events at daily timescales.

Keywords: Data visualization, tropical cyclones, rainfall data, information visualization, relationship data, visualization paradigms.
\end{abstract}

\section{Introduction}

The data collected to the present date with respect to storms are numerous and some of them date back more than half a century. In order to analyze these data and to get more out of them, visualizations become an important tool in their analysis. In this case, we propose a tool that visually overlays data showing which geographic areas are most affected by these atmospheric phenomena with the intention of trying to better predict which areas will be affected in the future by similar circumstances.

\subsection{Databases}

This visualization project emerged via a request made by the Centro de Investigaciones Geofísicas (CIGEFI) of the University of Costa Rica to the iReal research group (of the Instituto Tecnológico de Costa Rica). CIGEFI supplied all the tracking data, along with wind speed velocities, of all the tropical cyclones occurring over the last 50 years. As in [30], information of the trajectories and other characteristics of tropical cyclones at hourly time steps from 1970 to 2010 were obtained from the combination of two databases: HURDAT from the United States (US) National Hurricane Center and Central Pacific Hurricane Center part of the National Oceanographic and Atmospheric Administration and the tracks of the 
most recent cyclones were obtained from Unisys database from the repositories of the US National Aeronautics and Space Administration.

The project required relating dates on which heavy rainfall was reported in Central America with the positions of tropical cyclones on those same days. As part of the research, they proposed that the iReal group develop a visualization of 40 years of data (from 1970 to 2010), made up of these two sets of data. The visualization will serve as a key tool for CIGEFI scientists to apply in their work to determine critical positions of the tropical cyclones associated with extremely heavy rainfall events at daily timescales.

Three databases were utilized:

1. A list of 88 weather stations distributed throughout Central America with their corresponding geographic coordinates (see [30] for the metadata information of the meteorological stations).

2. All the daily rainfall data from those stations in the applicable years - consisting of more than 110,000 data items.

3. The dates, storm category and daily positions of all the tropical cyclones that occurred during these years.

Using this information as a guide, we proceeded to generate a database of the days in which each station reported rainfall greater than its 9oth percentile. This approach was taken because each region has its own climatic conditions, and therefore we were interested in the identification of extreme events relatively to each site's local climate.

Moving forward, the first action undertaken was to generate a script in Processing 3.1 (for details, see Section 4: Technical Background) to run all the data from the rainfall database (DB2) and to make a new database DB4 that only consisted of the data with rainfall daily accumulations greater than the 9oth percentile for each station over the 40-year period.

The next step was to generate another new database (DB5) recording the days when the stations experienced those extreme conditions, which would allow for assessing whether there were tropical cyclones present on those same days and for pinpointing their locations (see Figures 1 and 2 for the details about the databases generated).

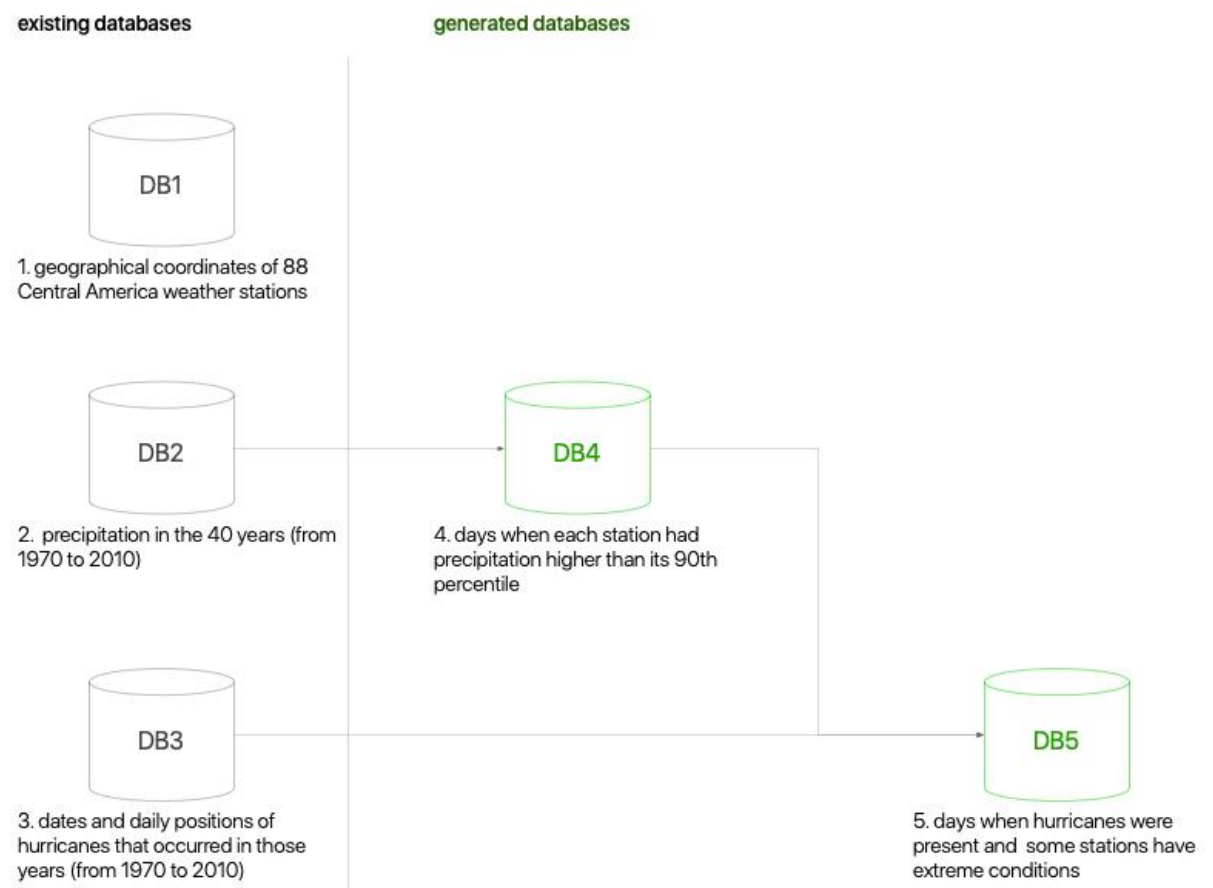

Fig. 1. Relationships between existing databases and project-generated databases. 


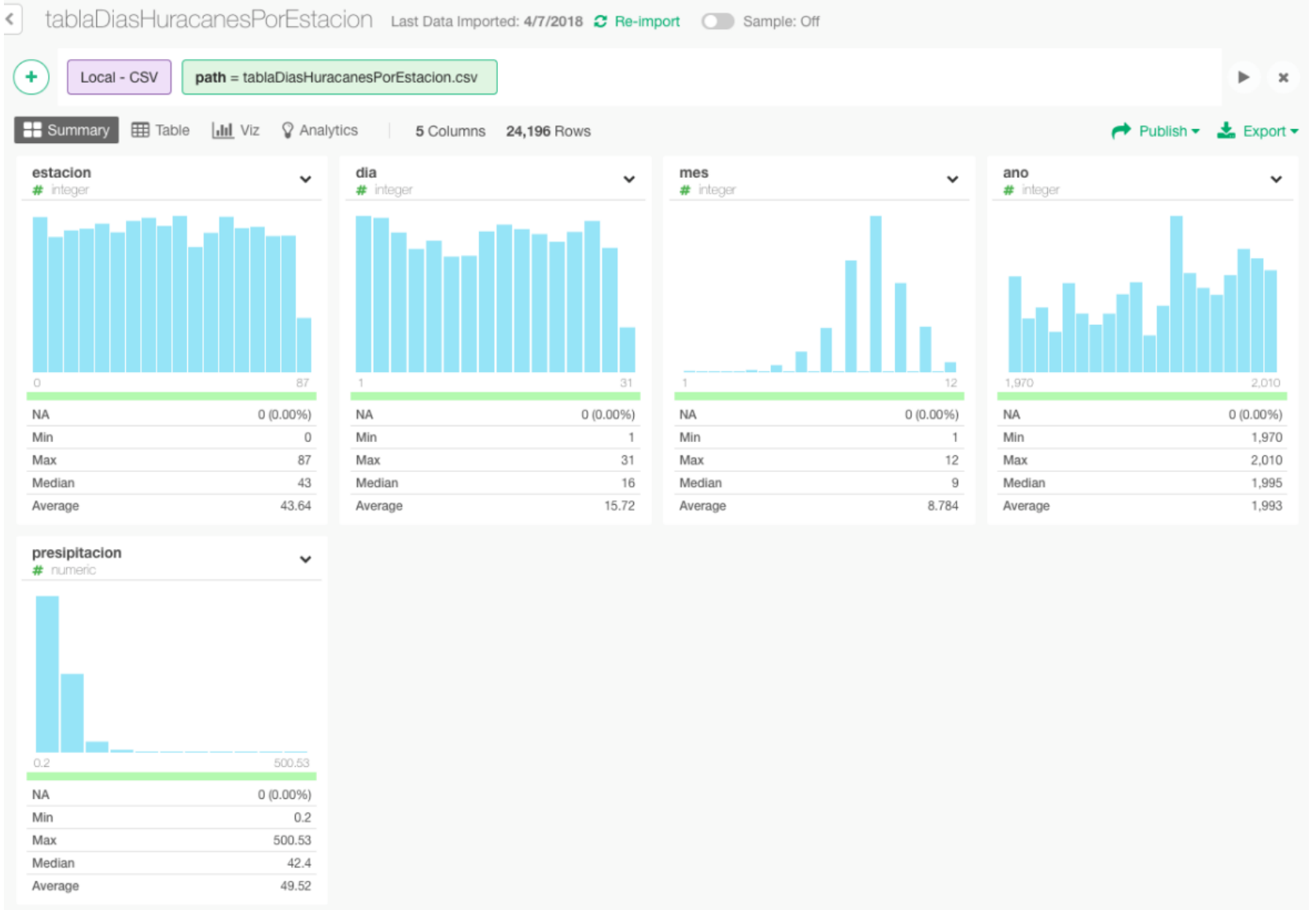

Fig. 2. Summary of the DB5 database, with 24,196 coincidences between days with the presence of hurricanes in the area and rainfall greater than the 9oth percentile in at least one weather station.

\subsection{Geographic area}

Two different tools were developed: one for the eastern Pacific and the other for the western Atlantic and Caribbean Sea.

The tool for the Pacific Ocean would take $[90,180] \mathrm{W}$ and $[0,30] \mathrm{N}$, and for the Atlantic Ocean (Caribbean Sea) $[100,50] \mathrm{W}$ and $[5,35] \mathrm{N}-$ Figure 3 shows the regions selected for our analysis.

These regions were defined based on predictions of which areas would prove important to the meteorologists' scientific hypotheses. 


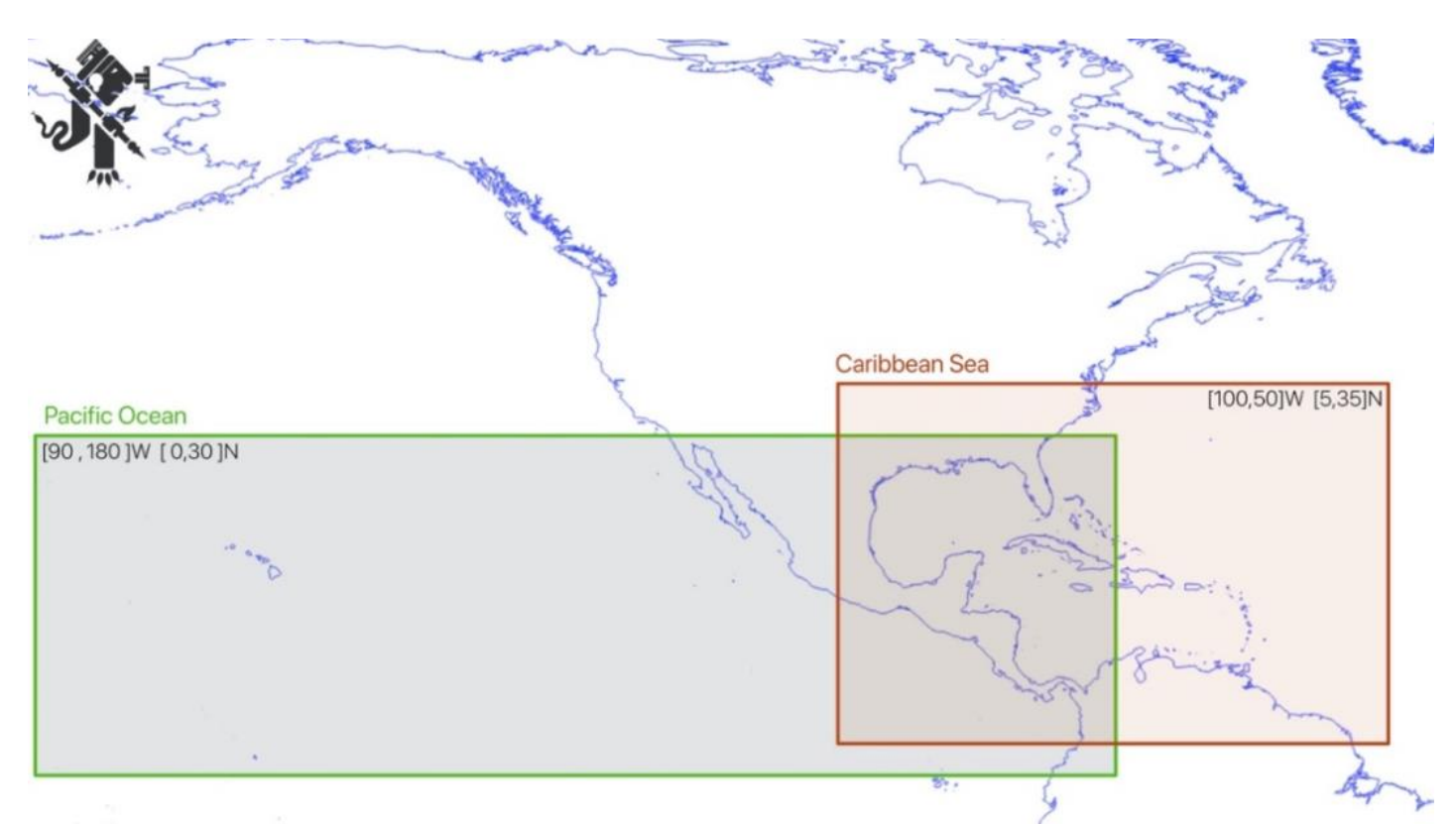

Fig. 3. Showing the display zones per tool.

\section{Related Works}

In a review of some research in this field, we found several approaches:

The works developed by [1], [2], and [3] are based on simulations of how hurricanes can impact coastal regions. Although in a similar context to ours, these studies focused on direct impacts rather than indirect ones [30], which is our focus.

Besides, research like [1] and [2], specialized in studying the behavior of trees and their branches, using 3D animation to depict their movements when impacted by hurricanes and storm flooding. In addition, in [3] authors recreate real-life cities in a $3 \mathrm{D}$ environment, providing a tool that allows for learning about storm surges.

On the other hand, as in [4], a new 3D system was implemented to highlight the real risks of when a storm surge is present. In doing so, the authors of [4] used the southern area of Miami Beach, Florida, as a model. Miami Beach is a city that lies about four to five feet (1.2$1.5 \mathrm{~m}$ ) above sea level, which makes it particularly vulnerable to surging waves. However, no one of the mentioned authors, adopts the specific topic that we are looking to analyze.

The available research has helped us to explore how tropical cyclones and their effects have been represented. However, no examples have focused on visualizing geographic zones or the passages and effects of meteorological phenomena.

Other studies have been focused on the analysis of a particular hurricane. For example, [5] aimed at developing a 3D immersive visualization of how Hurricane Lili (2002) changed from a Category $1(119-153 \mathrm{~km} / \mathrm{h})$ to a Category $4(209-251 \mathrm{~km} / \mathrm{h}$, Saffir-Simpson scale) in just 13 hours. The goal of the work was to exemplify the effectiveness of the $3 \mathrm{D}$ immersive virtual environments in the context of validating, evaluating, and refining the results of the models they normally use. In [6], they worked on tracking the trajectory of the tropical cyclone Karl (2010), which impacted Veracruz City in Mexico. And finally, Ko, Marks, Alaka, and Gopalakrishnan [7] evaluated the performance of attempts to predict rainfall from Hurricane Harvey in 2017.

In [8], the authors visualized the hurricane structure as a route to understand the physical processes that are immersed in this natural phenomenon, while [9] also shows another interesting visualization drawn from a simulation of the hurricane storm surge that produced flooding during Hurricane Katrina (2005). Their target is to improve the understanding of hurricanes and to prepare people in taking crucial decisions when they face them.

Other research seeks to reduce the uncertainty in predicting the paths of hurricanes. Cox, House, and Lindell [10], for example, explore the design of an alternate display to provide a 
continually updated set of possible hurricane tracks. In addition, [11] proposes an approach for generating smooth scalar fields from such a predicted storm path ensemble, allowing the user to examine the predicted state of the storm at any chosen time. And in [12], the work focused on how a visualization influenced the prediction of uncertain spatial trajectories, while [13] aimed at visualizing uncertain tropical cyclone predictions and, in [14], the researchers tested whether the different graphical displays of an uncertain hurricane forecast would influence decisions on storm characteristics. Plus, in [15], an interactive method was incorporated as an attempt at enhancing risk perception and understanding.

In [16], the authors present an interactive visualization system to explore global hurricane track data from 1851-2009. This visualization allows them to track thousands of hurricanes to show common patterns and to reveal outliers. This includes several dashboards to complement the visualization, which is fully linked to the hurricane data. The system allows for three different ways of observing the data: spatial position, time, and properties (wind, speed, pressure, and levels according to the Saffir-Simpson Hurricane Wind Scale which rating hurricane in five categories of wind speed, $1(119-153 \mathrm{~km} / \mathrm{h}), 2(154-177 \mathrm{~km} / \mathrm{h}), 3$ $(178-208 \mathrm{~km} / \mathrm{h}), 4(209-251 \mathrm{~km} / \mathrm{h})$, and $5(>252 \mathrm{~km} / \mathrm{h})$. Although this is an excellent visualization, it does not consider the influence that hurricanes have on other natural factors, such as rainfall.

The work of Knight and Davis [17] focused on a particular situation as they looked to analyze the contributions that tropical cyclones make to extreme rainfall events in the southeastern United States. They consider whether tropical cyclones have increased in intensity due to a rising trend in sea surface temperatures. Firstly, they used a $50.8 \mathrm{~mm}$ threshold to define extreme rainfall, supported by 85 surface weather observation stations. Although this work has similarities with ours, they do not utilize a visualization system or assess the subsequent interactivity it develops. Plus, more importantly, they use a single threshold to define 'extreme precipitation' at all stations, which is not desired in our case as we would like to take into consideration stations' very different precipitation local climate.

Similar research was also developed by Alfaro [18], in which the influence of the annual activity of tropical cyclones in the Atlantic and the variations of the sea surface temperature were studied. In doing so, they use a $2 \mathrm{D}$ map to show the hurricane paths. In [19], the goal was to create a visualization tool that easily demonstrates how precipitation extremes have changed and might change in the future.

Finally, in [20], Konrad and Perry carry out a study on the relationships between tropical cyclones and intense precipitation in the USA's Carolina region, in which they elaborate on the climatology of precipitation events for the period 1950-2004.

Although being excellent, the previous studies do not go into depth on analyzing the relationships between the two datasets, i.e., tropical cyclones positions and precipitation in the Central American isthmus surrounding areas, and not only on the coasts. The present study also delves into how the visualization itself - together with its possibilities and adjustments - can assist a better identification of the relationships under scrutiny.

\section{Visualization Design}

\subsection{Overview}

As a project summary, the visualization attempts to show the positions of the tropical cyclones at times when the weather stations reported high rainfall.

By indicating what information needed specifying, and based on the Objective Questions methodology [21], it was determined that the interface should show at least the following elements (see Figure 4):

1. The green dots represent the position of each weather station that is part of the study.

2. The red dots denote the positions of the hurricanes during the studied period. 
In addition, we have embraced the possibility of customizing the visualization according to requests from the scientists to help facilitate their work:

a. Types of tropical cyclones: it is possible to filter the intensity of the tropical cyclones by visualizing with buttons for $-4,-3,-2,-1,0,1,2,3,4,5-$ where -4 to 0 include system categories like low pressures, tropical depressions, subtropical storms, and tropical storms, while buttons 1 onward are reserved for hurricane with their respective categories (in the Atlantic-Caribbean Sea \& eastern Pacific Ocean).

3. Stations by country: these buttons allow for selecting all the stations of a country at the same time.

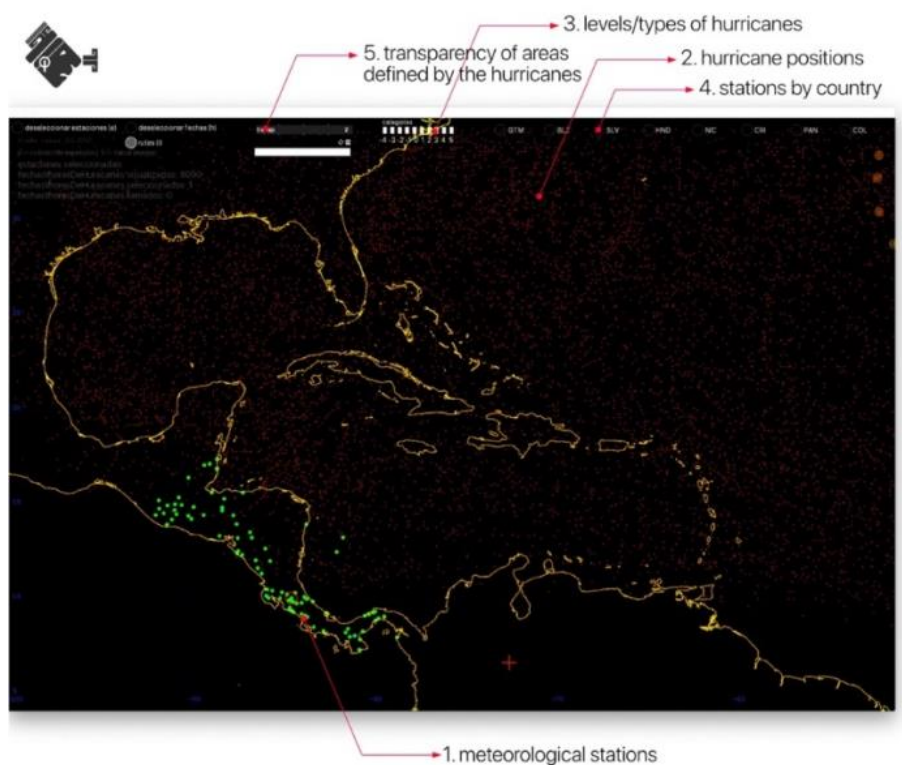

Fig. 4. Interface basic elements.

When a station is selected, it 'highlights' the points where hurricanes have occurred on the days when that station has had rainfall greater than its $90^{\text {th }}$ percentile. Figure 5 , for example, shows a selected station in El Salvador accompanied by the Pacific Ocean tropical cyclones associated with high rainfall in that area.

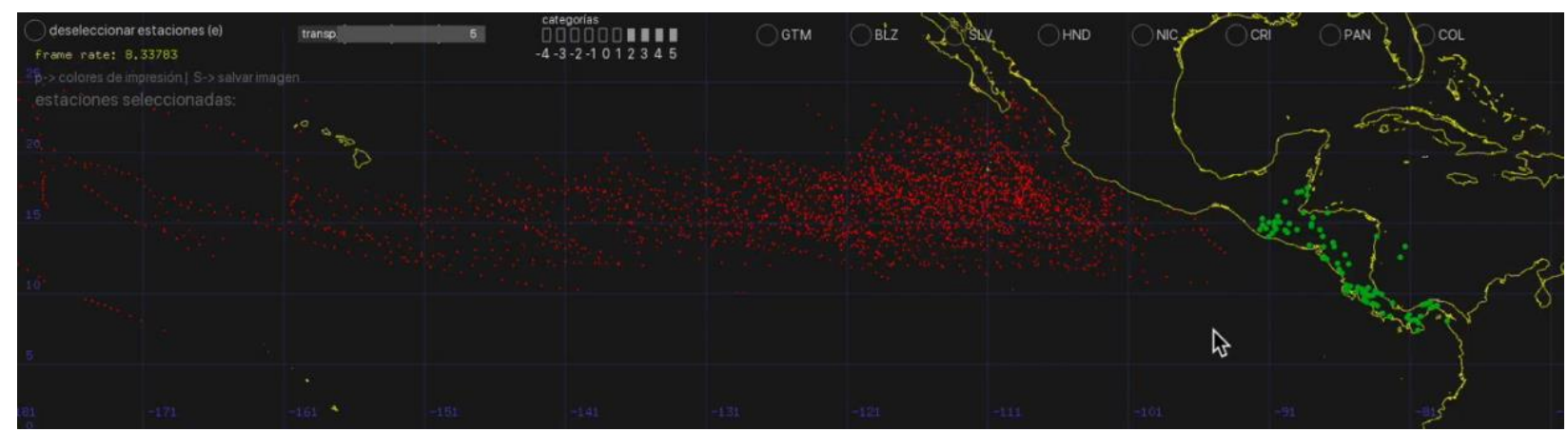

Fig. 5. Animation. Visualization showing a selected station in El Salvador and the positions of typhoons coinciding on days when that part of the country had severe rainfall conditions.

\subsection{Tropical cyclone visualization}

Several tests were made to determine how the hurricanes were to be visualized and, after trialing several options, the summation method was selected - a method that the research group had already used in several previous projects [22], [23], [24], [25] and [26]. The idea behind this strategy is that, if visualizing an area where a summation of events has occurred is the desired result, then each event is visualized with a very subtle color degradation and 
transparency. Thus, the areas featuring numerous results, after a summation of the subtly displayed events, become more evident than those with just a few, which remain very subtle and so lose importance in the overall view.

In the case of tropical cyclones, a red circle was used, which is more dense in the center and becomes more transparent toward the edges (Figure 6).

Fig. 6. Circle showing the color degradation with which a hurricane is visualized.

So, when several tropical cyclones are recorded in one area, the intensities of the visualizations increase, and a greater concentration of color is apparent. This is precisely what the scientists are looking for as they try to identify "common" areas where several tropical cyclones have passed over 40 years of study, and which correspond to heavy rains in one or several stations. In this way, they can identify areas where, if a future tropical cyclone happens to pass, then this could indicate risks of high rainfall in certain meteorological stations.

To better manage this effect, a slider was also added (point 5 in Figure 4), which allows for controlling the transparency of these red circles. This allows for adjusting the color intensity for analyses of cases with a small number of associated events, in contrast to cases that show many.

Figure 7 shows the same selection of stations but with different opacities in the red circles of the associated tropical cyclones.

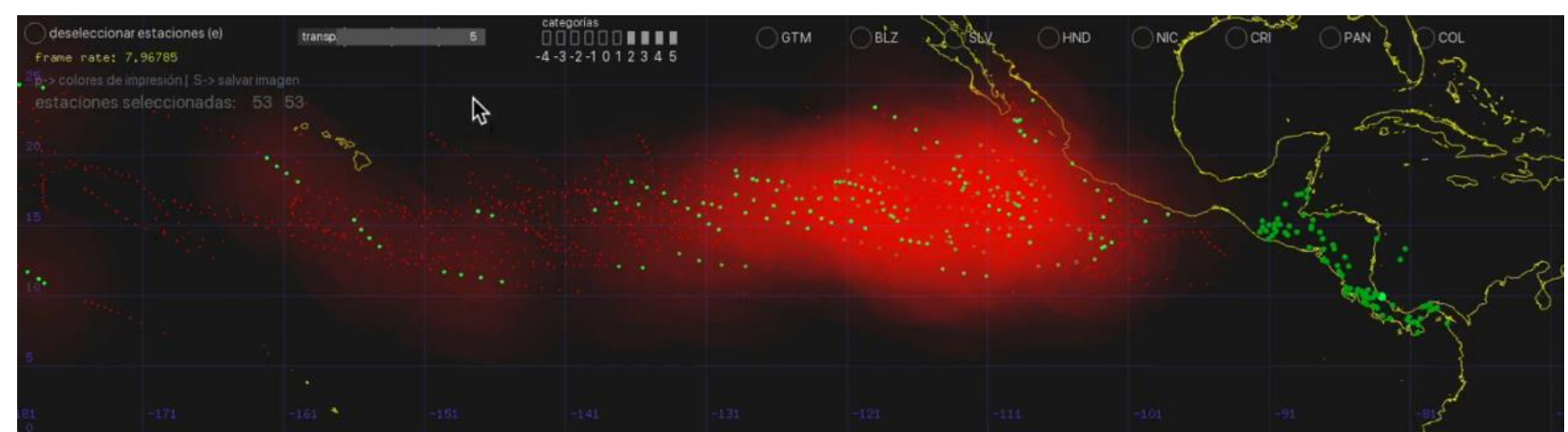

Fig. 7. Animation. Same station selection (Puerto Limón station in Costa Rica) but with two opacity values in the slider.

\subsection{Association between objects}

When utilizing the tool, it is possible, as we have seen, to select one or several stations to produce a visualization of tropical cyclone positions, but it is also possible to select a single tropical cyclone's position (or several tropical cyclones) to see which stations were affected when that tropical cyclone was in that position or, in other words, which stations recorded heavy rainfall on that same day.

Figure 8 shows a selected date/position to show where Hurricane 75 was on September 17, 1978. At that time, this hurricane was a Category 2 with a latitude of 15.2 and longitude of -81.6 - as shown in the pop-up text. 


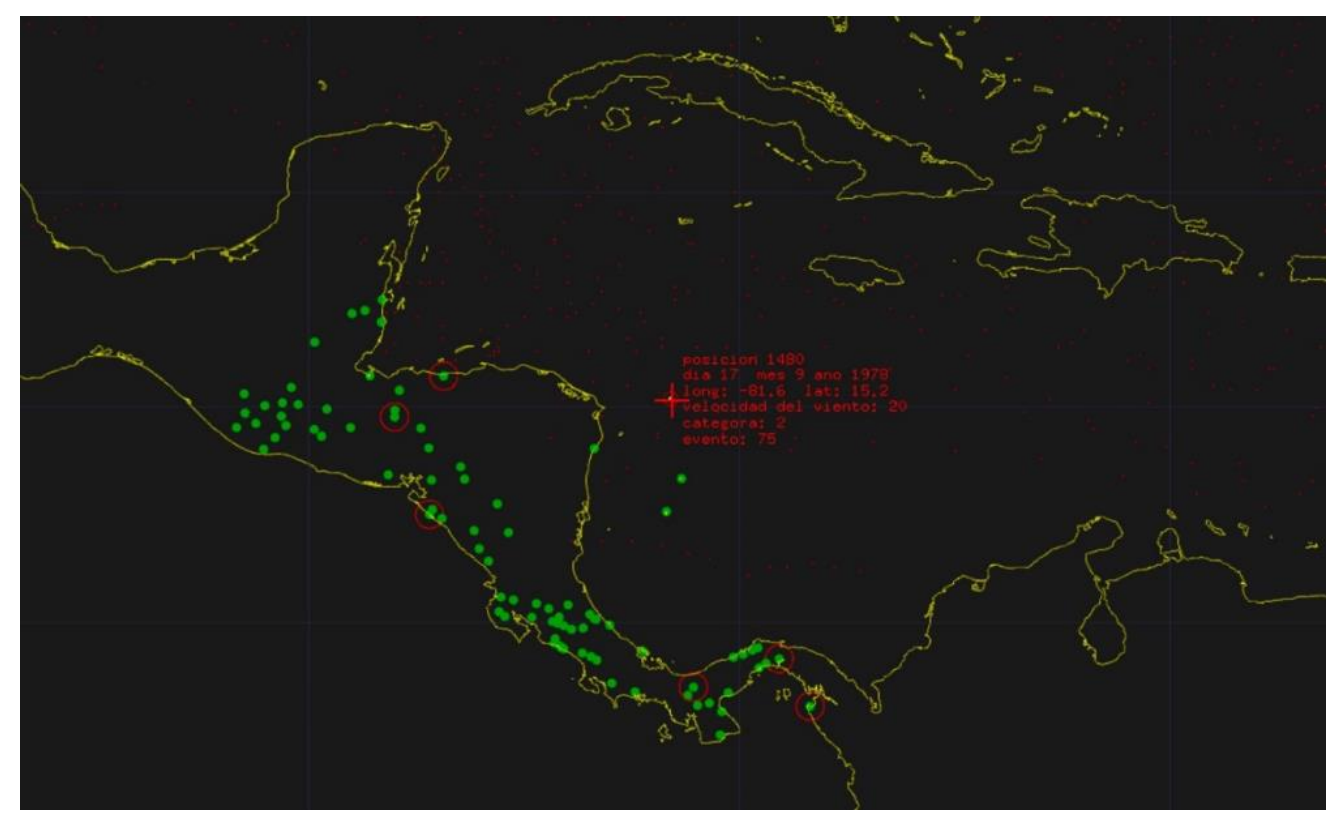

Fig. 8. Shows a selected hurricane dated September 17, 1978.

As seen in the Figure 8, the stations that recorded extremely high rainfall on that day are now shown with a red circle around them. Note, this is not the same as selecting the stations, as doing so would "illuminate" all the tropical cyclones that caused heavy rainfall at those stations during the 40-year period, i.e., in this case, the analysis can be adjusted to favor either the tropical cyclones or stations depending on your research purposes. The visualization allows for analyzing this other possibility. In Figure 9, we see another example featuring three positions of a hurricane in the Gulf of Mexico. The result is that the corresponding stations (where heavy rains occurred on the same days) appear as red rings.

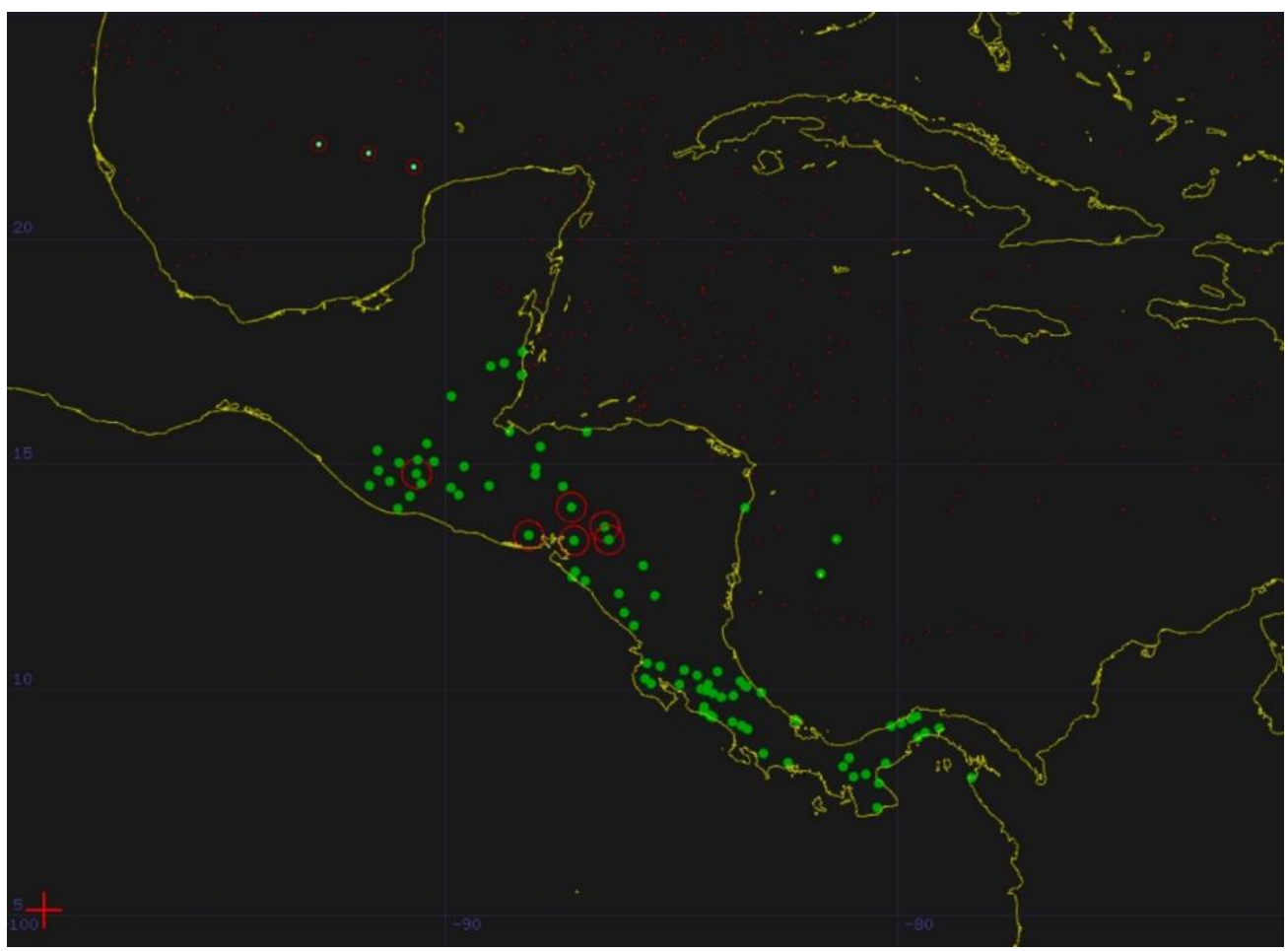

Fig. 9. Three selected hurricane positions near the Yucatan Peninsula in the Gulf of Mexico and the corresponding associated stations. 


\subsection{Chromatic codes}

To define the chromatic codes, basic heuristic tests were performed [27] and chromatic scales were defined based on the Küppers model [28], which corresponds to the HueSaturation-Value color model.

The idea behind the color-use definitions was to achieve a good contrast between the two groups of elements - the stations and the tropical cyclones. Figure 10 shows the position in the chromatic model.
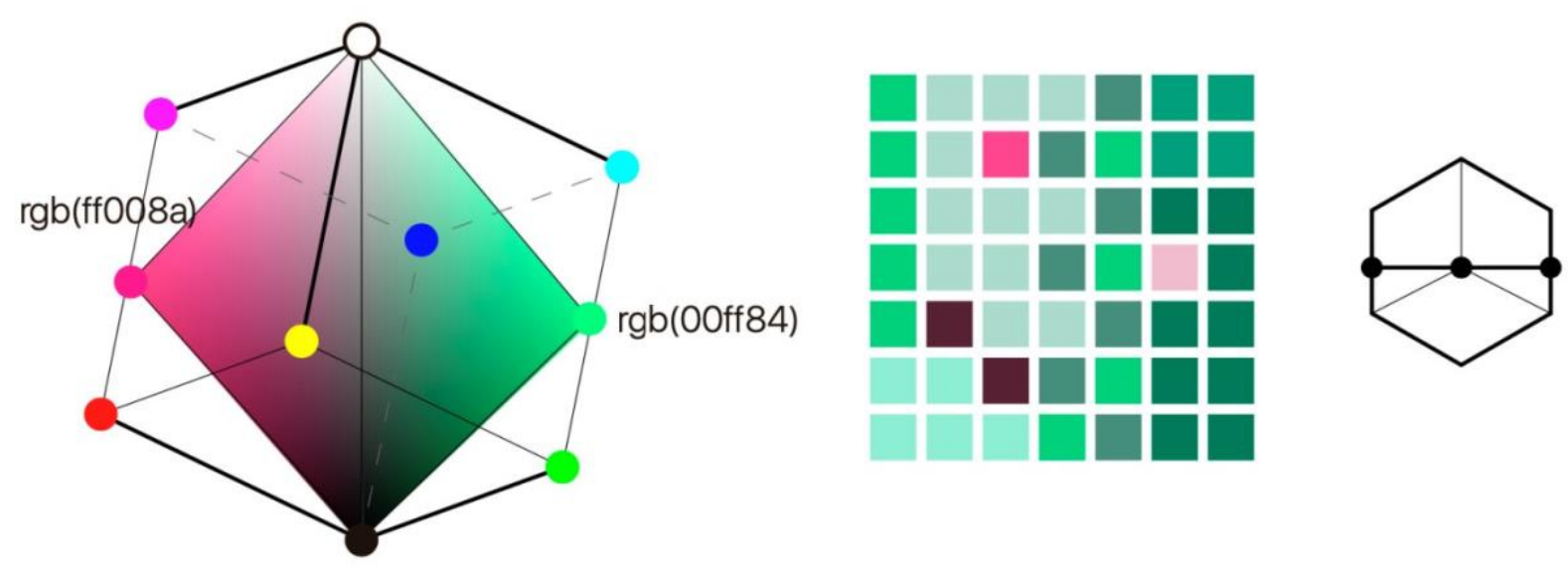

Fig. 10. Used chromatic composition in the Küppers model of the Hue-Saturation-Value color model, figure taken from F. Hernández-Castro. Teoría del color (ingredients) [5].

Once the basic colors were defined, we worked on the associations in order to show belongings according to the current selection.

In general, there are only three types of status:

1. Showing the positions of tropical cyclones and stations only, with no selections.

2. Showing the selected stations to reveal the positions of associated tropical cyclones.

3. Showing the selected tropical cyclones to reveal the associated stations.

Both hurricanes and stations can appear as three modes:

1. Passive mode.

2. Selected.

3. Showing that it is associated with another (or several) selected elements.

Red was selected for the tropical cyclone color and green for the stations. So, when a station (green) is selected the centers of the associated tropical cyclones also change to green to indicate their association with that station. In addition, they show the red zone of influence with transparency to collaborate in the chromatic saturation of the zone - as discussed in section 3.2.

On the other hand, when a tropical cyclone is selected, red rings (tropical cyclone color) appear in the associated stations, to show where high rainfall occurred on that specific date or dates.

Figure 11 shows this relationship between selected tropical cyclones and the stations associated with them. 


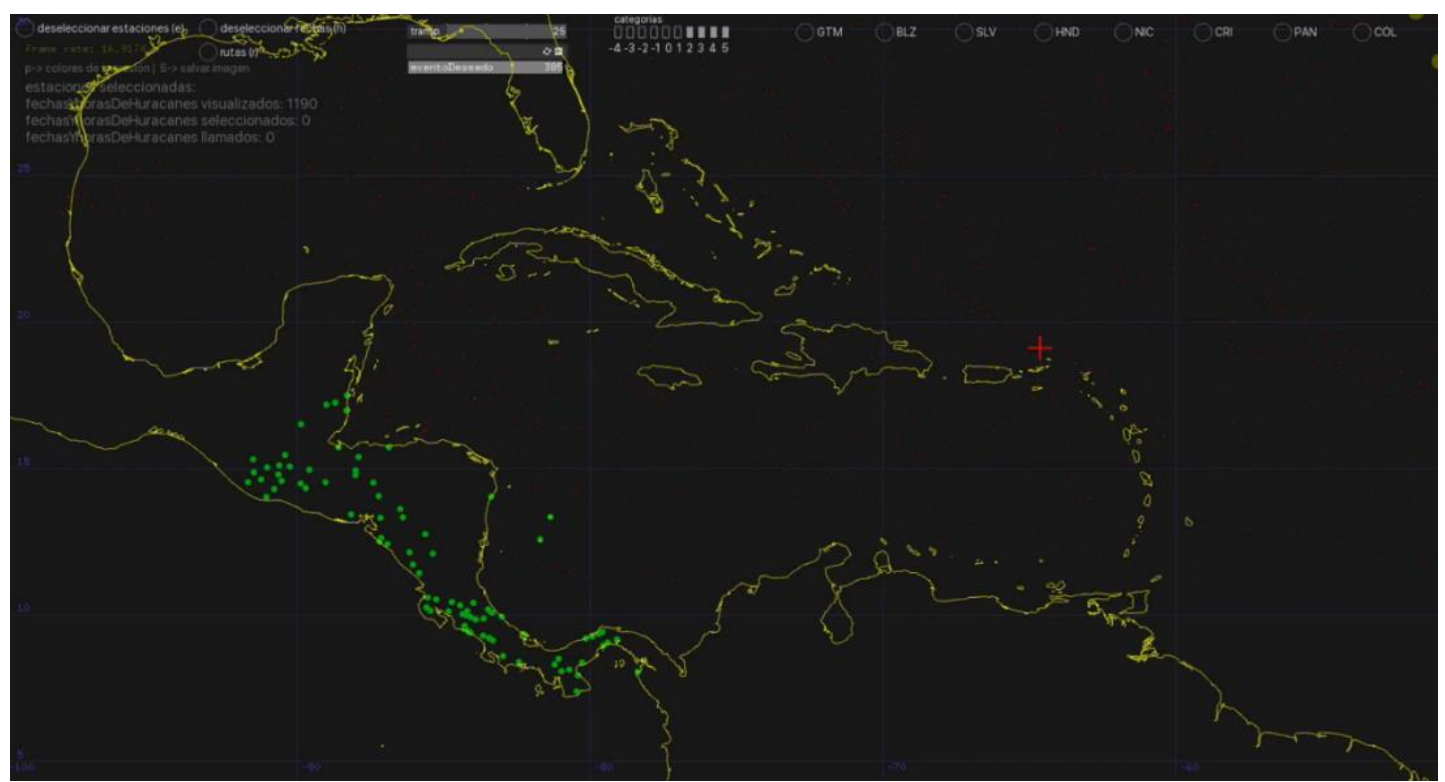

Fig. 11. Animation. Relationship between selected tropical cyclones and their associated stations.

\subsection{Tropical cyclone tracks}

In addition to the above-mentioned features, a button was included to allow for visualizing the historical paths of the different tropical cyclones. Because the points represent dates, a single hurricane has several dates in its route, that is to say, a variety of associated points. Thus, being able to visualize the routes of hurricanes is useful to know which points (or dates) belong to a specific hurricane. See Figure 12.

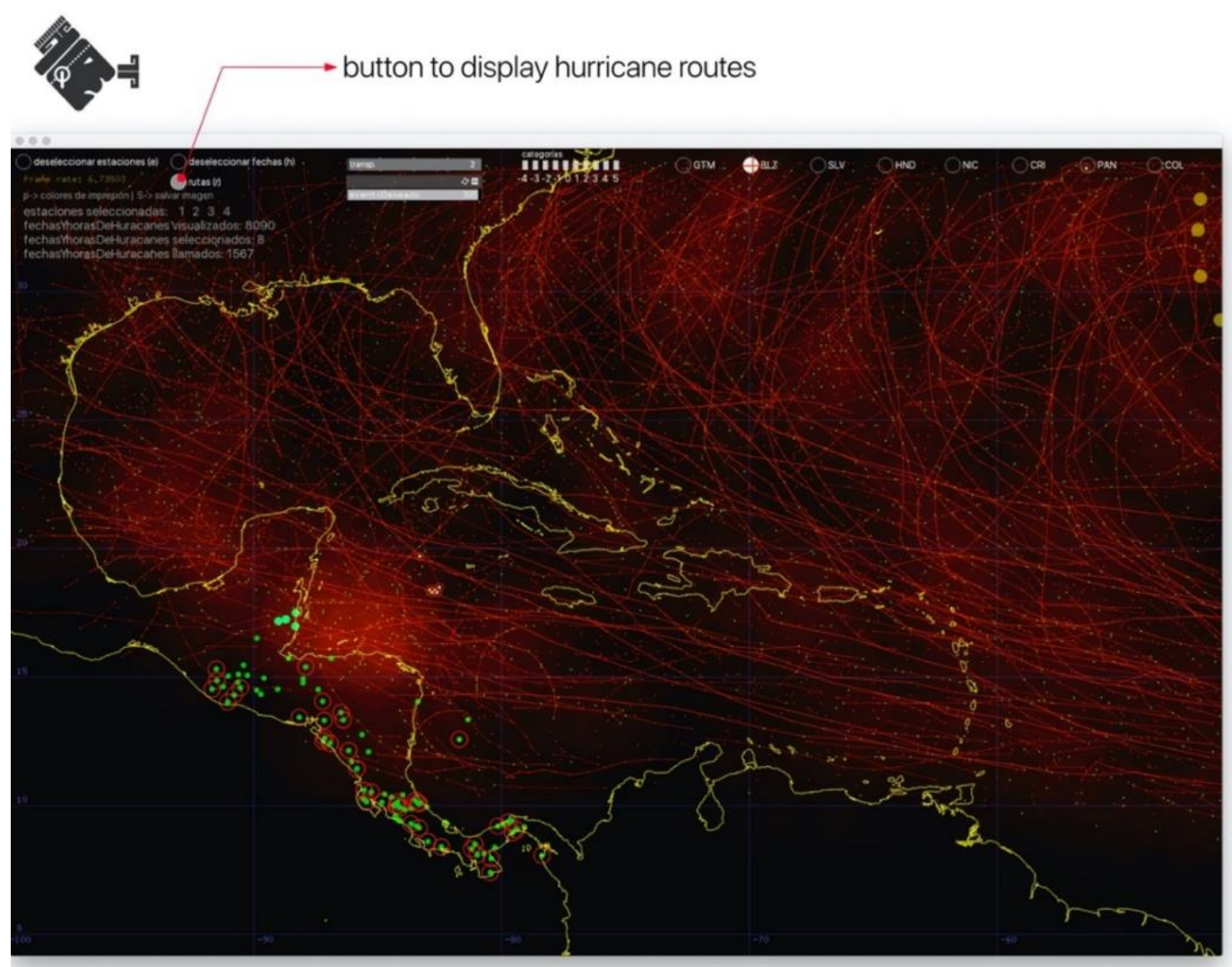

Fig. 12. Visualization showing the tropical cyclone paths. 


\subsection{Print view}

Both tools (Atlantic and Pacific) include an option to choose more paper-friendly colors. This feature was requested by scientists in order to obtain images for inclusion in their scientific papers. See Figure 13.

On-screen, the dark background colors are used but pressing the "p" key allows for switching to print colors.

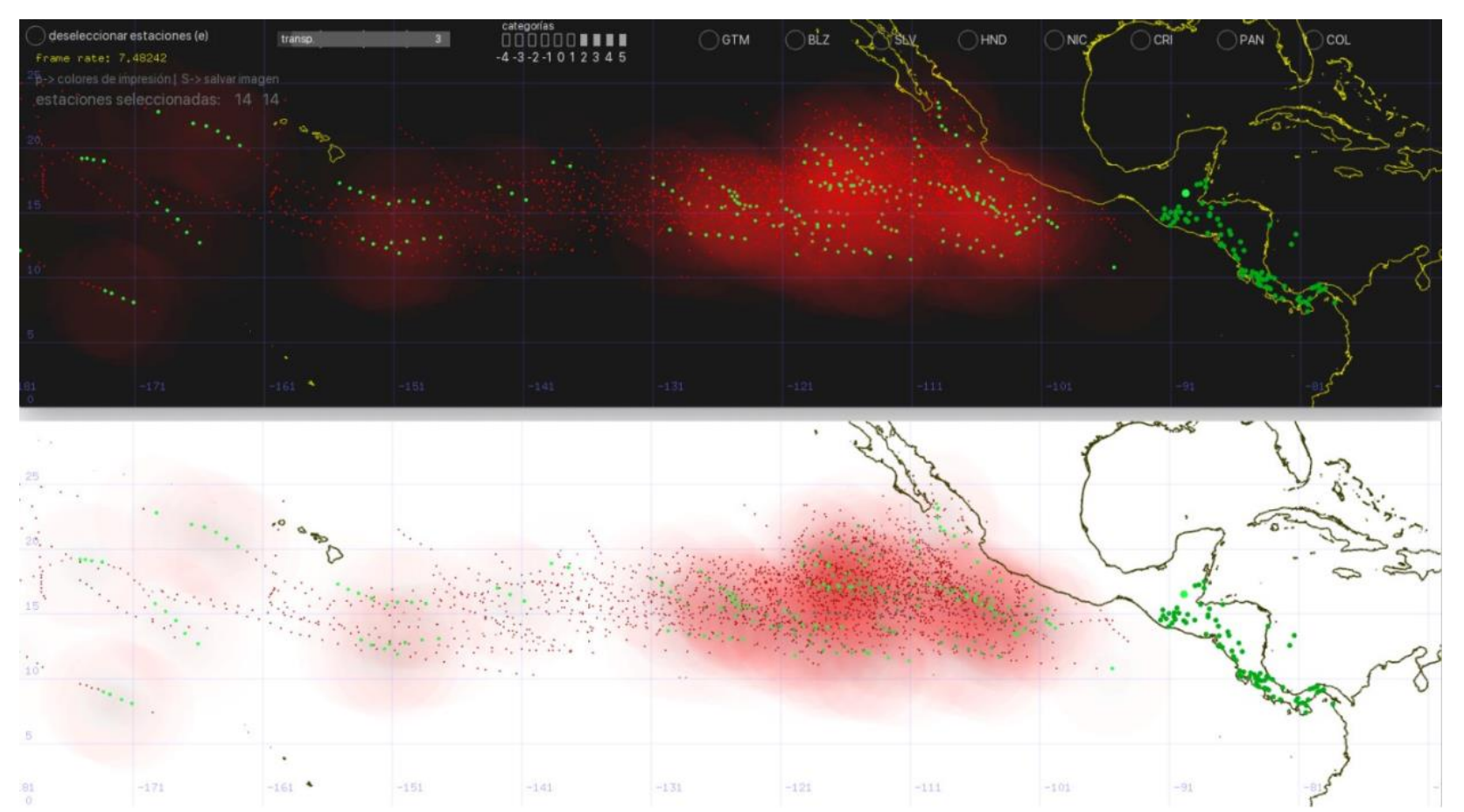

Fig. 13. Same data displayed in screen colors and paper-friendly colors.

\section{Technical background}

For previous visualizations [23], the iReal group had conducted a separate analysis [29] to select the platform with which to work on these projects.

After considering some available options, we decided to work with Openframeworks (https://openframeworks.cc), which is an open-source toolkit available from the C++ programming language and runs on scientists' three most popular platforms: Microsoft Windows, Apple macOS, and GNU/Linux.

\subsection{Data preparation}

The Processing programming language (https://processing.org), which is a dialect of Java, was used to create the database parse (see Figure 1). This environment was selected for this task due to the many functions it has already programmed for working with CSV and JSON files, in addition to being freely accessible.

The results were corroborated in Exploratory (https://exploratory.io), which is a tool that can be used free of charge and allows for the exploration of large amounts of data (see Figure 2).

\subsection{Background maps}

To obtain a good resolution georeferenced map, we used the polygon database of the world map accessible via the Nature Earth portal (https://www.naturalearthdata.com), where various types of geographic data from all over the planet can be downloaded with different resolutions and different attributes, all freely accessible.

In our case, working with a relatively small geographic area, the medium resolution of one datum every 100 meters was used, although the portal does provide resolutions of up to 
one datum every 10 meters. The map was exported to JSON file that was translated to CSV because the Openframeworks handling of this type of file is more efficient.

In this case, a CSV file was built in which each polygon of the map is a collection of points representing the vertices of the polygon (e.g., an island). To separate one polygon from another, a row of the file was used with an indicator that would only mark the end of one polygon and the beginning of the next. The number 2000 was used for this, since no latitude or longitude data could have this value, showing unequivocally the end and the beginning of each polygon - see Figures 14 and 15.

\begin{tabular}{|l|l|}
\hline 2000 & 2000 \\
\hline-61.19176184799994189 & 12.86823151200007942 \\
\hline-61.19082597599992823 & 12.85586172100005342 \\
\hline-61.18761145699994586 & 12.85639069200004769 \\
\hline-61.18358313699991413 & 12.86200592700004108 \\
\hline-61.1749568349999322 & 12.88178131700004769 \\
\hline-61.18317623599995159 & 12.88349030200004108 \\
\hline-61.19176184799994189 & 12.86823151200007942 \\
\hline 2000 & 2000 \\
\hline-87.72629342699991639 & 13.19838743700006489 \\
\hline-87.7271874399999092 & 13.21111475700007531 \\
\hline-87.71991332599992575 & 13.21619097200004944 \\
\hline-87.70608658799994828 & 13.21172623600006091 \\
\hline
\end{tabular}

Fig. 14. Structure of the CSV file for displaying the map.

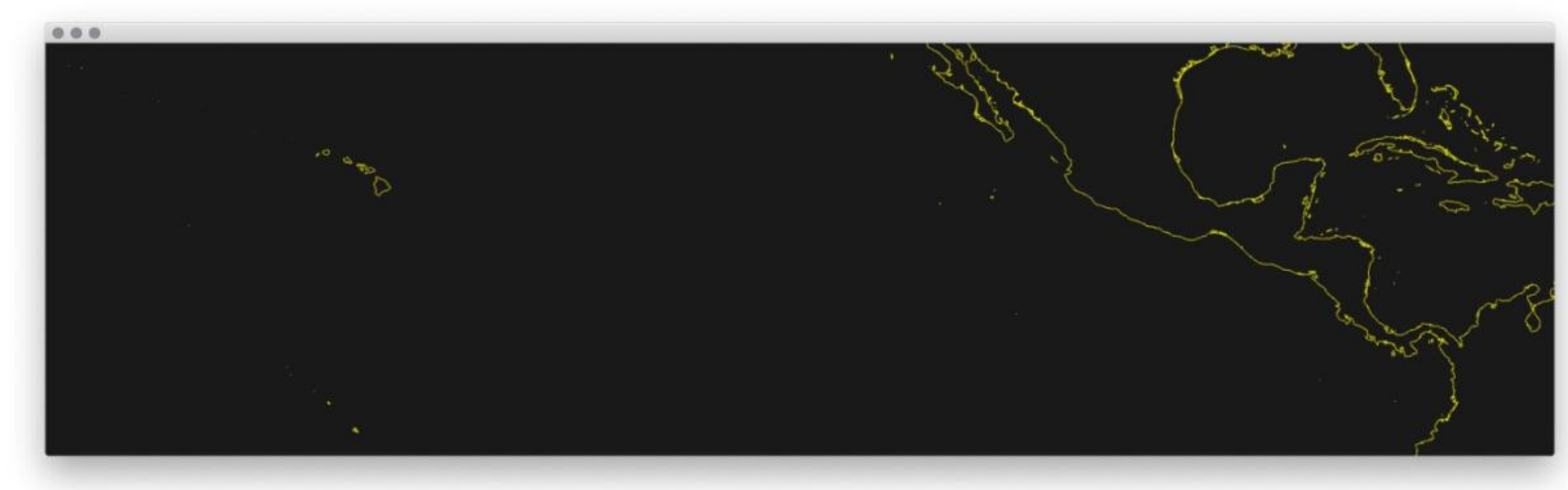

Fig. 15. Geo-referenced map ([90, 180] W $[0,30] \mathrm{N})$ used for the Pacific Ocean viewer.

\subsection{Structure of data}

As explained in Figure 2, two databases were generated from the three available databases, and these are the ones that were finally used in the project; one with the days in which each station reported rainfall greater than its 9oth percentile and the other with all the hurricanes' positions over the 40-year period - see Figure 16. 


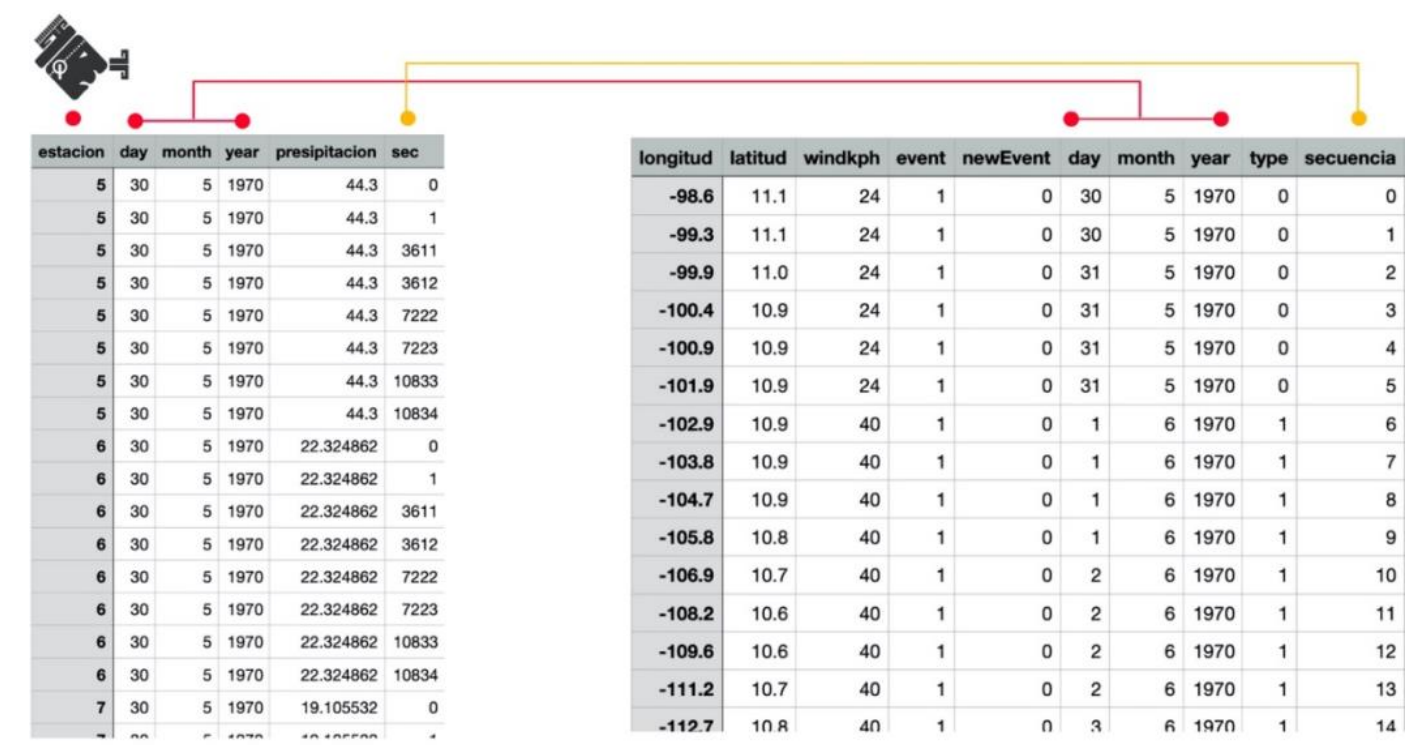

DB4. Days when stations reported precipitation greater than their 90 th percentile

DB5. Daily hurricane positions between 1970 and 2010

Fig. 16. Structure of the data generated for the tool.

The strategy was to have the days per station input into a database so that, when a station is selected, a search of those same dates is made in the hurricane database in order to "highlight" the hurricanes' positions on those days. With this structure, the application was able to respond efficiently and in real-time.

\subsection{Application logo}

The schools involved in the project, on the part of Tecnológico de Costa Rica, are the School of Industrial Design and the School of Mathematics; so, the School of Industrial Design was asked to design a logo for the application a study was made and a logo generated (see Figure 17) inspired by the Mayan legend of the god Huracán-Caculhá, from where it is believed that the original word for "hurricane" comes.
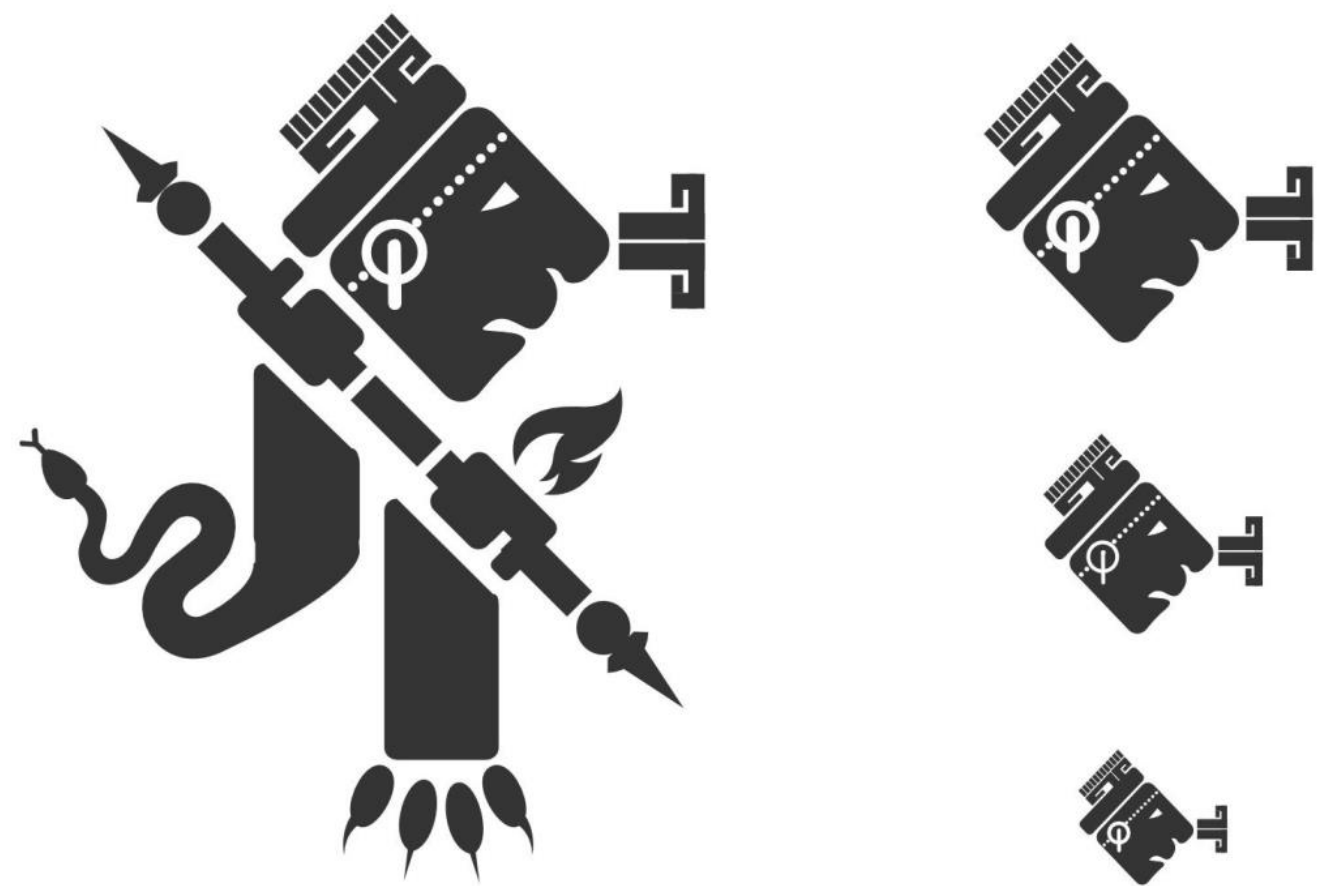

Fig. 17. The petroglyph where the abstraction for the logo of the application were taken from and samples of the icon in several sizes. 


\section{Usability evaluation}

As explained at the beginning, this project was explicitly requested by the scientists of the Centro de Investigaciones en Geofísica (CIGEFI) of the University of Costa Rica and was developed with their support throughout.

Several heuristic validations were performed at different stages of development. At each stage "use cases" were defined, each use case corresponded to tasks to be performed by the users.

In each case was valued: (1) effectiveness (if they achieved the objective of the task), (2) efficiency (how long it took), and (3) satisfaction (collection of comments on the use of the tool). With this information, the design team made the necessary corrections to improve the use of the tool. Indeed, the tool has already been used to analyze data. The results of these analyses have already helped to generate relevant contributions to the field [30].

\section{Conclusion and Future Work}

The tool met the development expectations, for which the immediate use and efficacy of the tool [30] by scientists is proof.

Thanks to this success, the possibility of continuing to benefit from visualized climaterelated data is currently being analyzed in cooperation with CIGEFI and the iReal Group.

\section{Acknowlegment}

The iReal research group would like to thank the scientists of the Centro de Investigaciones en Geofísica (CIGEFI) of the University of Costa Rica for their support and help throughout all stages of this project.

Hugo Hidalgo and Eric Alfaro wish to acknowledge the funding of this research to the projects B9-454 (VI- Grupos), EC-497 (FEES-CONARE), Co-610 (Fondo de Estímulo), A4906 (PESCTMA- CIGEFI), Co-074, A1-715 and Bo-810 from the Center for Geophysical Research (CIGEFI) of the UCR. We give thanks to the UCR School of Physics for giving us the research time to develop this study. Also, we would like to thank the UCR research center CIGEFI for their logistic support during the data compilation and analysis, and the Central American NW \& HSs for providing the rain gauge data used in this work.

Finally, we give thanks to the eScience research program to which our iReal Group belongs, which has supported this project in all administration and funding aspects.

\section{References}

1. P. A. Singh, N. Zhao, S.C. Chen \& K. Zhang. Tree animation for a $3 \mathrm{D}$ interactive visualization system for hurricane impacts. In 2005 IEEE International Conference on Multimedia and Expo (pp. 598-601). IEEE, July, 2005.

2. K. Saleem, S.C. Chen \& K. Zhang. Animating tree branch breaking and flying effects for a 3 d interactive visualization system for hurricanes and storm surge flooding. In Ninth IEEE International Symposium on Multimedia Workshops (ISMW 2007) (pp. 335-341). IEEE, December, 2007.

3. M.E.P. Reyes \& S.C. Chen. A $3 \mathrm{D}$ virtual environment for storm surge flooding animation. In 2017 IEEE third international conference on multimedia big data (BigMM) (pp. 244-245). IEEE, April, 2017.

4. K. Zhang, S.C. Chen, P. Singh, K. Saleem \& N. Zhao. A 3d visualization system for hurricane storm-surge flooding. IEEE Computer Graphics and Applications, 26(1), 18-25, 2006.

5. J. Sanyal, P. Amburn, S. Zhang, P.J. Fitzpatrick \& R. J. Moorhead. 3D immersive visualization and evaluation of mesoscale model outputs simulating hurricane Lili's (2002) rapid weakening. In OCEANS 2008 (pp. 1-8). IEEE, September, 2008. 
6. M.G. Ramírez, K.E. Á Román \& E. G. E. Fernández. Seguimiento de la trayectoria del huracán "Karl" hasta impactar la costa de Veracruz, mediante imágenes de satélite en septiembre del 2010.

7. M.C Ko, F.D. Marks, G. J. Alaka \& S.G. Gopalakrishnan. Evaluation of hurricane Harvey (2017) rainfall in deterministic and probabilistic HWRF forecasts. Atmosphere, 11(6), 666, 2020.

8. A. Joshi, J. Caban, P. Rheingans\& L. Sparling. Case study on visualizing hurricanes using illustration-inspired techniques. IEEE Transactions on Visualization and Computer Graphics, 15(5), 709-718, 2008.

9. D. Irby, M.J. Mohammadi-Aragh, R. Moorhead \& P. Amburn. Improving the understanding of hurricanes: Visualizing storm surge. In OCEANS 2009 (pp. 1-4). IEEE, October, 2009.

10. J. Cox, D. House \& M. Lindell.Visualizing uncertainty in predicted hurricane tracks. International Journal for Uncertainty Quantification, 3(2), 2013.

11. L. Liu, M. Mirzargar, R. M. Kirby, R. Whitaker \& D. H. House. Visualizing TimeSpecific Hurricane Predictions, with Uncertainty, from Storm Path Ensembles. In Computer Graphics Forum (Vol. 34, No. 3, pp. 371-380), June, 2015.

12. A. J. Pugh, C. D. Wickens, N. Herdener, B. A. Clegg \& C. A. P. Smith. Effect of visualization on spatial trajectory prediction under uncertainty. In Proceedings of the Human Factors and Ergonomics Society Annual Meeting (Vol. 61, No. 1, pp. 297-301). Sage CA: Los Angeles, CA: SAGE Publications, September, 2017.

13. L. Liu, L. Padilla, S.H. Creem-Regehr\& D. H. House. Visualizing uncertain tropical cyclone predictions using representative samples from ensembles of forecast tracks. IEEE transactions on visualization and computer graphics, 25(1), 882-891, 2018.

14. I. T. Ruginski, A. P. Boone, L. M Padilla, L. Liu, N. Heydari, H.S. Kramer, , ... \& S. H. Creem-Regehr. Non-expert interpretations of hurricane forecast uncertainty visualizations. Spatial Cognition \& Computation, 16(2), 154-172, 2016.

15. B. L. Lindner, J. Johnson, F. Alsheimer, S, Duke, G. D. Miller \& R. Evsich. Increasing risk perception and understanding of hurricane storm tides using an interactive, Web-based visualization approach. Journal of Coastal Research, 34(6), 1484-1498, 2018.

16. Z. Wang, H. Guo, B. Yu \& X. Yuan. Interactive Visualization of 160 Years' Global Hurricane Trajectory Data. In Proceedings of the IEEE Pacific Visualization Symposium (Poster), Hong Kong (pp. 37-38), March, 2011.

17. D. B. Knight \& R.E. Davis. Contribution of tropical cyclones to extreme rainfall events in the southeastern United States. Journal of Geophysical Research: Atmospheres, 114(D23), 2009.

18. E. J. Alfaro. Escenarios climáticos para temporadas con alto y bajo número de huracanes en el Atlántico. Revista de Climatología, 7, 2007.

19. R. Phinney. Visualizing Extreme Precipitation for Climate Storytelling, 2018.

20. C. E. Konrad \& L. Perry. B. Relationships between tropical cyclones and heavy rainfall in the Carolina region of the USA. International Journal of Climatology: A Journal of the Royal Meteorological Society, 3o(4), 522-534, 2010.

21. F. Hernandez-Castro, J. Monge-Fallas. "What for: classification of visual paradigms." PONTE: International Scientific Researches Journal, Vol. 72, No. 7, 2016.

22. F. Hernandez-Castro, J. Monge-Fallas, L. Rodríguez, D. Solís. (2019). Skygraph: visualizing Costa Rica's winds. PONTE: International Scientific Researches Journal, 75(4/1), 2016.

23. F. Hernández-Castro \& J. Monge-Fallas.VISUALIZING WIND FIELDS IN COSTA RICA. Scientific Visualization. 12(3): 1 - 15, DOI: 10.26583/sv.12.3.01, 2020.

24. J. Monge-Fallas. F. Hernández-Castro. An Intuitive 3D Interface for Defining Seismic Profiles by Plinius. PONTE: International Scientific Researches Journal, 74(4), 2018.

25. F. Hernández-Castro, J. Monge-Fallas. Plinius: A Visualization System of Costa Rica's Tectonic Plates. Scientific Visualization;11(2), 73-78. DOI: 10.26583/sv.12.3.0, 2019. 
26. F. Hernandez-Castro, J. Monge-Fallas. Navigation Sphere: Optimizing Virtual Sphere for Terrains Analyses. PONTE: International Scientific Researches Journal. Jul;74(7). DOI: 10.21506/j.ponte.2018.7.3, 2018.

27. F. Hernández-Castro. Metodología para el análisis y diseño de aplicaciones (usability cookbook). Escuela de Diseño Industrial, Instituto Tecnológico de Costa Rica. Cartago, Costa Rica. Repositorio TEC: https://repositoriotec. tec. ac. cr/handle/2238/6776, 2016.

28. F. Hernández-Castro. Teoría del color (ingredients). Escuela de Diseño Industrial, Instituto Tecnológico de Costa Rica. Cartago, Costa Rica. 2016.

29. F. Hernández-Castro \& J. Monge-Fallas. Eficiencia comparativa en animaciones en javascript (nota técnica). Tecnología en Marcha. Vol. 31-3. Julio-Setiembre 2018. Pág 143150.

3o. H. Hidalgo, E. Alfaro, F. Hernández-Castro, P. Pérez-Briceño. Identification of Tropical Cyclones' Critical Positions Associated with Extreme Precipitation Events in Central America. Atmosphere 11, no. 10 (2020): 1123. 